\title{
A INDÚSTRIA DO FITNESS E SEU DESENVOLVIMENTO DESIGUAL: UM ESTUDO SOBRE AS ACADEMIAS DE GINÁSTICA NA CIDADE DE GOIÂNIA
}

\author{
Dennia Pasquali \\ Universidade Federal de Goiás, Goiânia, Goiás, Brasil \\ Ricardo Niterói \\ Universidade Federal de Goiás, Goiânia, Goiás, Brasil \\ Fernando Mascarenhas \\ Universidade de Brasília, Brasília, Distrito Federal, Brasil
}

\begin{abstract}
Resumo: Este artigo resulta de uma investigação sobre a lógica de desenvolvimento da "Indústria do Fitness". A partir do estudo de caso, buscamos cotejar as tendências de expansão desta "Indústria" com dados referentes ao contexto de Goiânia-GO. Foi construída uma caracterização quantitativa do mercado e realizada uma pesquisa qualitativa, envolvendo observação e entrevistas, junto a 10 academias do município. Concluiu-se que o crescimento deste setor segue a lógica de desenvolvimento desigual, com a oposição entre grandes academias, que demonstram enorme capacidade de inovação, distribuindo-se pelos centros mais dinâmicos da cidade, e as pequenas academias que proliferam na periferia, baseadas em métodos tradicionais de organização do trabalho e dependentes do consumo local.
\end{abstract}

Palavras chave: Fitness; Academias de Ginástica; Goiânia.

\section{Introdução}

As práticas corporais têm ocupado lugar de relevo na sociedade contemporânea. Todavia, distinta de suas manifestações em época anterior, articuladas ao ambiente escolar e a Educação Física, às políticas sociais de esporte e lazer ou ao associativismo dos clubes recreativos, as atuais experiências em torno da corporalidade estão cada vez mais subordinadas à forma de mercadoria. Ocorre que, sob o padrão da acumulação flexível, amplos segmentos empresarias voltam seus investimentos para setor de serviços. Neste contexto, aumenta a oferta e o consumo dos serviços ligados ao lazer e ao entretenimento, o que envolve as práticas corporais comercializadas em academias de ginástica. Como existem limites para a acumulação e para o giro de bens físicos, não é de estranhar que o mercado se volte para o fornecimento de serviços bastante efêmeros em termos de consumo (HARVEY, 2000).

Em investigação anterior, buscamos avaliar a lógica de desenvolvimento que orienta o crescimento do mercado relativo ao setor de fitness, isto é, da "Indústria do Fitness". ${ }^{1}$ Pudemos confirmar que no âmbito da produção e consumo das práticas

\footnotetext{
${ }^{1}$ A noção de "Indústria do Fitness", vinculada ao processo de produção e distribuição das práticas corporais nas academias de ginástica, é desdobrada aqui do conceito de "Indústria Cultural" (ADORNO;
}

Pensar a Prática, Goiânia, v. 14, n. 2, p. 1-15, maio/ago. 2011 
corporais por esta "Indústria", em sintonia com o processo mais geral de "mundialização da cultura" (ORTIZ, 1994), estão presentes traços e evidências de um envolvente processo que se espalha pelo mundo, definindo formas de sociabilidade, amoldando subjetividades, modificando e definindo hábitos, valores e comportamentos.

Nesta perspectiva, nosso problema investigativo consistiu em identificar as características, contradições e implicações desta lógica, que é global, em nível local. A partir do estudo de caso, buscamos cotejar os dados referentes ao mercado de GoiâniaGO as tendências gerais que caracterizam o desenvolvimento da "Indústria do Fitness" em escala mundial.

\section{A Indústria do Fitness e seu desenvolvimento desigual}

A "Indústria do Fitness" vem apresentando uma enorme expansão. Embora sejam pouco confiáveis as fontes e escassos os dados sobre o seu desenvolvimento, se tomamos como referência os números sistematizados no Atlas do Esporte no Brasil, ${ }^{2}$ podemos indicar o início da década de 1970 como o momento de conformação em base nacional de uma "proto-Indústria Fitness", 3 quando operavam no país algo em torno de mil academias de ginástica. Este quantitativo, aferido em 1971 pelo Diagnóstico da Educação Física e do Desporto, saltou para 20 mil em 2003, deste total, 12 mil unidades registradas e sindicalizadas e 8 mil micro e pequenos negócios, números que expressam enorme crescimento.

Em 2003, conforme dados da Internetional Health, Raqueth e Sportsclub Association (IHRSA), também compilados no Atlas do Esporte no Brasil, comparativamente, o Brasil só ficava atrás dos EUA em número de academias.

Tabela 1: Número de academias por países líderes, 2003

\begin{tabular}{|c|c|c|}
\hline Posição & País & Número total de academias \\
\hline $1^{\text {o }}$ & Estados Unidos & 23.000 \\
\hline $2^{\text {o }}$ & Brasil & 20.000 \\
\hline $3^{\circ}$ & Alemanha & 6.500 \\
\hline $4^{\circ}$ & Inglaterra & 4.000 \\
\hline
\end{tabular}

Fonte: Atlas do Esporte no Brasil (2006)

É importante destacar, no entanto, que se em número de academias o Brasil é o segundo no ranking, ao tomarmos como referência o número de usuários e o índice de consumo - que equivale ao percentual de consumidores dos serviços de academias em relação à população de cada país -, as posições se invertem, configurando um cenário diferente.

HORKHEIMER, 1985), vinculada ao processo mais geral de padronização e racionalização das técnicas de produção e distribuição dos bens e serviços culturais mercantilizados.

${ }^{2}$ Disponível em http://www.atlasdoesportenobrasil.org.br. Acesso em 5 set. 2008.

${ }^{3}$ Em termos gerais, a proto-industrialização ou proto-indústria corresponde ao período marcado pela existência de indústrias primitivas, que podem ser descritas como indústrias manufatureiras. A idéia de uma "proto-Indústria Fitness", aplicada ao contexto brasileiro, caracteriza o momento em que o processo de trabalho no setor de academias estava mais próximo a modelo tradicional, de caráter artesanal, sem o devido incremento dos princípios e técnicas da organização científica do trabalho. Sobre a adesão do setor a modernas técnicas de organização do trabalho, ver: Pinheiro e Pinheiro (2006).

Pensar a Prática, Goiânia, v. 14, n. 2, p. 1-15, maio/ago. 2011 
Tabela 2: Número de usuários e percentual da população por países líderes, 2003

\begin{tabular}{|c|c|c|c|}
\hline Posição & País & Número de usuários & Índice de consumo \\
\hline $1^{\text {o }}$ & Estados Unidos & 33,2 milhões & $13,2 \%$ \\
\hline $2^{\text {o }}$ & Inglaterra & 5,1 milhões & $8,9 \%$ \\
\hline $3^{\mathrm{o}}$ & Alemanha & 4,6 milhões & $5,7 \%$ \\
\hline $4^{\mathrm{o}}$ & Brasil & 3,4 milhões & $2,0 \%$ \\
\hline
\end{tabular}

Fonte: Atlas do Esporte no Brasil (2006)

O que estamos buscando evidenciar é que os dados referentes à expansão da poderosa "Indústria do Fitness" estadunidense, líder do mercado mundial, quando cotejado com os da brasileira, apontam para uma lógica de desenvolvimento desigual, partindo dos centros dinâmicos que determinam as diferenças de ritmo de crescimento do setor. Neste particular, o reposicionamento do Brasil, expresso pelo seu baixo índice de consumo - apenas $2 \%$ de nossa população se exercitam em academias de ginástica -, reflete a defasagem da "Indústria do Fitness" no país, indicando o potencial de exploração do mercado nacional.

Alertamos que tais números apagam as desigualdades intramercados. A noção de "Indústria do Fitness" não pode, como já alertado, nos induzir a uma idéia de homogeneidade. O processo de desenvolvimento do capital é cada vez mais marcado pela tendência ao monopólio, o que se expressa pela formação de grandes conglomerados empresariais, muitas vezes de base transnacional (BRAVERMAN, 1987), o que se verifica também no setor de academias. Neste sentido, podemos dizer que em seu movimento expansivo, a "Indústria do Fitness" polariza grandes e pequenas academias. $^{4}$

Se voltarmos aos países líderes, os números referentes à expansão da "Indústria do Fitness" estadunidense, cotejados com os da brasileira, indicam uma dinâmica diferente quanto ao crescimento do setor. Se dividimos o número total de academias pelo número de usuários, nota-se nos Estados Unidos a proporção de 1 academia para cada 1.443 mil usuários, enquanto no Brasil temos 1 academia para cada 170 usuários. Nesta razão, quando da observância dos números referentes ao crescimento nos últimos anos do quantitativo de academias no país, podemos facilmente deduzir que, combinado ao crescimento das grandes academias, o que cresceu por aqui, em grande parte, foi o contingente das pequenas academias.

Feita esta aproximação, tendo como pressuposto o desenvolvimento desigual que embala a "Indústria do Fitness", é nosso objetivo estudar o comportamento do mercado goianiense, examinando sua dinâmica e configuração territorial, bem como buscando identificar e comparar os traços definidores das grandes academias e suas diferenças em relação pequenas academias da cidade.

\footnotetext{
${ }^{4}$ Para se ter um exemplo, segundo estudo da Associação Brasileira de Academias (ACAD), em 2001, do universo aproximado de quase 7.000 estabelecimentos focados produção do fitness no Brasil, 94\% podiam ser consideradas academias de pequeno porte, responsáveis em seu conjunto por um faturamento inferior a R\$ 1 milhão. Por sua vez, a maior academia do país à época, a Runner, de São Paulo-SP, dispôs no mesmo ano de 24.000 alunos e faturou, sozinha, aproximadamente R\$ 25 milhões. Disponível em http://www.site.acadbrasil.com.br/. Acesso em 5 set. 2008.
}

Pensar a Prática, Goiânia, v. 14, n. 2, p. 1-15, maio/ago. 2011 


\section{As academias de ginástica na cidade de Goiânia}

Em princípio, para a quantificação das academias em Goiânia, valemo-nos de levantamento junto aos websites da Prefeitura Municipal, Junta Comercial de Goiás (JUCEG), Conselho Regional de Educação Física (CREF) e listas telefônicas. Depois de verificada a indisponibilidade de dados junto a Prefeitura, buscados virtual e presencialmente, foi constatada também a impossibilidade de consegui-los através da JUCEG. ${ }^{5}$ Já os dados obtidos a partir do website do CREF não permitiram acesso aos endereços das academias, informação essencial à investigação, o que foi possível de ser apurado somente através da Telelistas ${ }^{6}$ e da Lista Telefônica on line ${ }^{7}$. Através destas fontes, mediante busca operada a partir dos descritores "academia" e "academia desportiva", bem como posterior cruzamento dos resultados, consolidamos uma lista de 182 academias, com a respectiva identificação de seus endereços e telefones.

A partir da listagem produzida, foi realizada a tentativa de contato telefônico com todas as academias, quando, em caráter exploratório, foram também solicitadas algumas informações de domínio público. Após as ligações, o total decresceu de 182 para 123 academias, constatado um alto índice de números inexistentes, seja pelo cancelamento da assinatura telefônica ou pelo próprio fechamento da academia. ${ }^{8}$ A partir deste universo de 123 academias, depois do georreferenciamento realizado através do Google Maps Brasil ${ }^{9}$, foi possível vislumbrar a distribuição territorial e construir uma caracterização geral do mercado goianiense.

\section{Aspectos gerais do mercado}

\section{- Distribuição territorial}

A começar pelo georreferenciamento, pudemos ter uma visão geral da distribuição territorial das academias, que se configura do seguinte modo:

\footnotetext{
${ }^{5}$ A Secretaria Municipal de Desenvolvimento Econômico (SEDEM) é responsável pelos registros relativos ao alvará de localização e funcionamento, porém não disponíveis ao público. No caso da JUCEG, os dados somente são disponibilizados frente o pagamento de taxas cobradas por cada registro consultado, o que, financeiramente, inviabilizou sua consulta.

${ }^{6}$ Disponível em http://www.telelistas.net. Acesso em 10 set. 2008.

${ }^{7}$ Disponível em http://www.listaonline.com.br. Acesso em 10 set. 2008.

${ }^{8}$ A taxa de mortalidade das micro e pequenas empresas no Brasil, medida pelo Serviço Brasileiro de Apoio às Micro e Pequenas Empresas (SEBRAE, 2005), indica que 22\% fecham as portas antes mesmo de completarem dois anos. Embora não existam estudos específicos sobre o setor de academias, avaliamos que esta tendência incide também sobre o setor de academias. Neste particular, é importante destacar que a fiscalização de estabelecimentos irregulares na cidade tem provocado o seu fechamento. De acordo com números da Prefeitura, divulgados através da matéria "Goiânia, terreno livre para a ilegalidade", no jornal O Popular, de 25 jan. 2009, 11 mil estabelecimentos foram notificados em 2008 porque não atendiam às exigências da lei, portanto, não possuíam alvará de localização e funcionamento. Deste total, 2,8 mil foram autuados e fechados. Outro dado importante, diz respeito à taxa de mortalidade das micro e pequenas empresas já mencionada a partir de dados do SEBRAE, que também incide sobre o setor de academias.

${ }^{9}$ Disponível em http://maps.google.com.br/maps. Acesso em 15 out. 2008.
}

Pensar a Prática, Goiânia, v. 14, n. 2, p. 1-15, maio/ago. 2011 
Tabela 3: Distribuição das academias por bairro na cidade de Goiânia, 2008

\begin{tabular}{|l|c|c|}
\hline \multirow{2}{*}{ Bairro } & \multicolumn{2}{c|}{ Academias } \\
\cline { 2 - 3 } & Número & Percentual \\
\hline Setor Bueno & 27 & $21,95 \%$ \\
\hline Setor Oeste & 12 & $9,75 \%$ \\
\hline Setor Sul & 11 & $8,94 \%$ \\
\hline Jardim América & 8 & $6,50 \%$ \\
\hline Setor Nova Suíça & 5 & $4,06 \%$ \\
\hline Setor Marista & 5 & $4,06 \%$ \\
\hline Setor Central & 5 & $4,06 \%$ \\
\hline Jardim Goiás & 5 & $4,06 \%$ \\
\hline Setor Universitário & 5 & $4,06 \%$ \\
\hline Outros bairros & 43 & $32,56 \%$ \\
\hline Fonte: Elaboračo prop & \\
\hline
\end{tabular}

Fonte: Elaboração própria (2008)

Conforme a demarcação das regiões metropolitanas - central, sul, sudeste, leste e norte - organizada pela Prefeitura, pode-se dizer que $67,44 \%$ das academias de Goiânia estão localizadas nas regiões central e sul, não coincidentemente, as regiões que concentram maior renda da capital. Em contrapartida 32,56\% das academias se dispersam por outros bairros e regiões.

\section{- Preços praticados}

Quanto à mensalidade, esta foi informada por 105 academias. Dentre estas, 63,8 \% cobram valores entre 50 e 100 reais, o que sugere um perfil de usuário que pode destinar cerca de $24 \%$ do salário mínimo - equivalente 415 reais em 2008 - para o consumo de serviços ligados às práticas corporais. Nos extremos, 2,85\% cobram acima de 200 reais mensais e $10,47 \%$ abaixo de 50 reais.

Tabela 4: Preços praticados pelas academias na cidade de Goiânia, 2008

\begin{tabular}{|l|c|c|}
\hline \multirow{2}{*}{ Valor da mensalidade } & \multicolumn{2}{|c|}{ Academias } \\
\cline { 2 - 3 } & Número & Percentual \\
\hline Abaixo de 50 reais & 11 & $10,47 \%$ \\
\hline Entre 50 e 100 reais & 67 & $63,8 \%$ \\
\hline Entre 100 e 150 reais & 21 & $20 \%$ \\
\hline Entre 150 e 200 reais & 3 & $2,85 \%$ \\
\hline Acima de 200 reais & 3 & $2,85 \%$ \\
\hline
\end{tabular}

Fonte: Elaboração própria (2008)

De acordo com o relatório de pesquisa de preços em academias de ginástica na cidade de Goiânia, realizada em 2008 pela Superintendência de Proteção aos Direitos do Consumidor de Goiás (PROCON-GO) ${ }^{10}$ nota-se uma situação semelhante, com o valor mensal cobrado pelo mesmo tipo de serviço ou prática corporal oscilando entre 35 e 280 reais de uma academia para outra, uma variação de preço de $700 \%$.

- Tempo de funcionamento

\footnotetext{
${ }^{10}$ Pesquisa realizada pelos técnicos do PROCON-GO junto a 9 academias de ginástica de Goiânia entre 3 e 4 mar. 2008. Disponível em: http://www.procon.go.gov.br/procon/detalhe.php?textoId=001316v. Acesso em 11 out. 2008.
}

Pensar a Prática, Goiânia, v. 14, n. 2, p. 1-15, maio/ago. 2011 
Quanto ao tempo de funcionamento das academias, 71 academias indicaram com precisão o tempo de existência do estabelecimento. Verificou-se que apenas $1,4 \%$ delas está no mercado há mais de trinta anos. Parcela significativa, $33,8 \%$, funciona a mais de 10 anos, mas a maioria, $47,88 \%$, abriu suas portas a menos de 10 anos.

Tabela 5: Tempo de funcionamento das academias na cidade de Goiânia, 2008

\begin{tabular}{|l|c|c|}
\hline \multirow{2}{*}{ Tempo de funcionamento } & \multicolumn{2}{|c|}{ Academias } \\
\cline { 2 - 3 } & Número & Percentual \\
\hline Menos de 5 anos & 17 & $23,94 \%$ \\
\hline Entre 5 e 10 anos & 17 & $23,94 \%$ \\
\hline Entre 10 e 20 anos & 24 & $33,8 \%$ \\
\hline Entre 20 e 30 anos & 12 & $16,9 \%$ \\
\hline Acima de 30 anos & 1 & $1,4 \%$ \\
\hline
\end{tabular}

Fonte: Elaboração própria (2008)

Este último dado indica que grande parte das academias de Goiânia emergiu na segunda metade da década de 1990, acompanhando o processo geral de expansão da "Indústria do Fitness" em escala global.

\section{- Professores empregados}

No que se refere ao número de professores, 107 academias informaram o quadro empregado. Destas, 39,62\% contam com somente um professor, e 27,35\% delas com dois professores. $\mathrm{Na}$ outra ponta, apenas uma academia emprega mais de 10 professores. Não foram levantados dados em relação ao número de estagiários, mas o percentual de $66,97 \%$ de academias que operam com até 2 professores sugere um sobrecarga de trabalho para tais professores, o que quase sempre resulta na contratação de mão-de-obra barata e precarizada.

Tabela 6: Quantidade de professores empregados por academia na cidade de Goiânia, 2008

\begin{tabular}{|l|c|c|}
\hline \multirow{2}{*}{ Quantidade de professores } & \multicolumn{2}{|c|}{ Academias } \\
\cline { 2 - 3 } & Número & Percentual \\
\hline 1 professor & 42 & $39,62 \%$ \\
\hline 2 professores & 29 & $27,35 \%$ \\
\hline 3 professores & 17 & $16,03 \%$ \\
\hline 4 professores & 6 & $5,66 \%$ \\
\hline Entre 5 e 10 professores & 11 & $10,3 \%$ \\
\hline Acima de 10 professores & 2 & $0,94 \%$ \\
\hline
\end{tabular}

Fonte: Elaboração própria (2008)

\section{- Serviços ofertados}

Em relação às praticas ofertadas, a musculação é a modalidade mais comum, âncora em $81,3 \%$ dos estabelecimentos, acompanhada pela ergometria, comercializada em $65,85 \%$ das academias. A ginástica localizada aparece somente em terceiro lugar presente em 39,83\% das unidades. E modalidades como hidroginástica e lutas, ambas em $32,52 \%$ das academias, estão também entre as mais ofertadas. Outro serviço que também merece atenção diz respeito à oferta dos programas de ginástica pré- 
coreografada da Body Systems ${ }^{11}$, franqueados por $10,56 \%$ das academias da cidade. Modalidades focadas em demandas e nichos específicos também estão presentes no mercado, tais como escalada, em uma academia, yoga, em 4,6\%. Isto sem falar do pilates, em 21,95\% dos estabelecimentos e da RPG, em 2,46\%.

Tabela 7: Serviços comercializados pelas academias na cidade de Goiânia, 2008

\begin{tabular}{|l|c|c|}
\hline \multirow{2}{*}{ Serviços } & \multicolumn{2}{|c|}{ Academias } \\
\cline { 2 - 3 } & Número & Percentual \\
\hline Musculação & 100 & $81,3 \%$ \\
\hline Ergometria & 81 & $65,85 \%$ \\
\hline Ginástica Localizada & 49 & $39,83 \%$ \\
\hline Hidroginástica & 40 & $32,52 \%$ \\
\hline Lutas & 40 & $32,52 \%$ \\
\hline Dança & 38 & $30,89 \%$ \\
\hline Esportes & 38 & $30,89 \%$ \\
\hline Jump & 36 & $29,26 \%$ \\
\hline Spinning & 28 & $22,76 \%$ \\
\hline Pilates & 27 & $21,95 \%$ \\
\hline Step & 15 & $12,19 \%$ \\
\hline Body Systems & 13 & $10,56 \%$ \\
\hline Outras práticas corporais & 13 & $10,53 \%$ \\
\hline Fonte: Elaboraça propria & & \\
\hline
\end{tabular}

Fonte: Elaboração própria (2008)

\section{Centro versus periferia}

Do universo das 123 academias georreferenciadas, seguindo a lógica da organização social da cidade, foram selecionadas 10 academias para a pesquisa de campo. Tendo em vista a configuração desigual da sociedade goianiense, apoiados em dados sistematizados pela Prefeitura, ${ }^{12}$ definimos como critério de seleção a distribuição de renda entre as regiões e bairros da cidade. Combinada a esta opção, a classificação das academias em "grandes" e "pequenas" foi outra referência utilizada. Furtado (2007) constrói tal classificação a partir de duas categorias fundamentais, a quantidade de alunos e a área construída, além de outras categorias subordinadas, como quantidade de professores e alunos, receita bruta, equipamentos etc, o que define a racionalização do processo de produção e organização do trabalho no interior de cada academia. Tendencialmente, a lógica de desenvolvimento da cidade, em grande medida, gera a fixação das "grandes academias" em bairros com economia mais dinâmica, o mesmo ocorrendo em relação às "pequenas academias" que, frente ao mercado concorrencial, ofertando serviços menos sofisticados, dispersam-se por toda a cidade, principalmente, entre os bairros de menor renda.

Todavia, ao passo que a dinâmica "centro" versus "periferia" pode revelar surpresas quanto à distribuição das riquezas pela cidade, o mesmo pode ocorrer em relação às academias, este foi um pressuposto. Em outros termos, sabia-se que

\footnotetext{
${ }^{11}$ A Body Systems é uma empresa franquedora que comercializa no Brasil e América Latina um sistema de mesmo nome que engloba programas de ginástica de grupo pré-coreografada, produzidos e distribuídos pela rede neozelandesa de academias Les Mills. Para saber mais, ver: www.bodysystems.net. ${ }^{12}$ Referimo-nos à pesquisa "Responsáveis pelos domicílios particulares permanentes por faixa de renda, em salários mínimos, segundo os bairros", organizada em 2002 pela a Secretaria Municipal de Planejamento (SEPLAN).
}

Pensar a Prática, Goiânia, v. 14, n. 2, p. 1-15, maio/ago. 2011 
"pequenas academias" poderiam ser encontradas em regiões mais centrais da cidade, embora o contrário fosse bem menos provável. Nesta direção, realizamos uma pesquisa de campo junto a 10 academias divididas em dois grupos representativos dos 5 bairros com população de maior renda e dos 5 bairros com população de menor renda da cidade.

Tabela 8: Dados socioeconômicos dos bairros com população de alta renda selecionados, 2002

\begin{tabular}{|l|c|c|c|}
\hline \multirow{2}{*}{$\begin{array}{c}\text { Bairros com população } \\
\text { de alta renda }\end{array}$} & \multicolumn{3}{|c|}{$\begin{array}{c}\text { Pessoas Responsáveis pelos domicílios e seu percentual por faixas de renda, } \\
\text { em salários mínimos }\end{array}$} \\
\cline { 2 - 4 } & Total de pessoas & Até 2 & Mais de 20 \\
\hline Setor Oeste & 8.331 & $2,82 \%$ & $40,93 \%$ \\
\hline Bairro Nova Suica & 1.795 & $4,45 \%$ & $36,88 \%$ \\
\hline Setor Marista & 2.421 & $4,99 \%$ & $35,93 \%$ \\
\hline Setor Bueno & 9.322 & $5,67 \%$ & $33,95 \%$ \\
\hline Setor Sul & 3.971 & $6,74 \%$ & $28,98 \%$ \\
\hline
\end{tabular}

Fonte: Prefeitura de Goiânia - SEPLAN (2002)

Tabela 9: Dados socioeconômicos dos bairros com população de baixa renda selecionados, 2002

\begin{tabular}{|l|c|c|c|}
\hline \multirow{2}{*}{$\begin{array}{c}\text { Bairros com população } \\
\text { de baixa renda }\end{array}$} & \multicolumn{3}{|c|}{$\begin{array}{c}\text { Pessoas Responsáveis pelos domicílios e seu percentual por faixas de renda, } \\
\text { em salários mínimos }\end{array}$} \\
\cline { 2 - 4 } & Total de pessoas & Até 2 & Mais de 20 \\
\hline Vila Concordia & 998 & $54,6 \%$ & $0,3 \%$ \\
\hline Jardim Novo Mundo & 9.520 & $44,14 \%$ & $1 \%$ \\
\hline Jardim Guanabara & 4.503 & $42,54 \%$ & $0,77 \%$ \\
\hline Bairro Goiá & 1.523 & $41,89 \%$ & $0,32 \%$ \\
\hline Setor Perim & 864 & $38,31 \%$ & $2,43 \%$ \\
\hline
\end{tabular}

Fonte: Prefeitura de Goiânia - SEPLAN (2002)

Assim, a pesquisa de campo envolveu a observação dos espaços e equipamentos, além de entrevista junto aos gestores de cada uma destas academias. ${ }^{13}$ Por sua vez, o tratamento dos dados se deu a partir de análise subsidiada pela revisão literária e construída segundo as tendências de desenvolvimento da "Indústria do Fitness". Feita a caracterização socioeconômica dos bairros selecionados, apresentamos as reflexões e conclusões geradas, buscando evidenciar as nuanças que envolvem a expansão do setor.

\section{As academias do centro}

\section{- Academia C1}

Situada no segundo andar de um shopping, a academia está no mercado há um ano e é bastante organizada, contando com $4.000 \mathrm{~m}^{2}$ distribuídos por várias salas orbitando em torno de uma maior destinada à prática da musculação, todas com ar condicionado. Seu proprietário é um investidor da área médica. Trabalham 40 professores e 4 estagiários, além de 11 funcionários de gestão e apoio. Ofertando 18 práticas corporais diferentes, destinadas ao público jovem e adulto, a academia conta também práticas focadas em grupos específicos, gestantes e grupo de corrida. Agrega serviços terceirizados instalados dentro da academia, tais como a avaliação física,

\footnotetext{
${ }^{13}$ A pesquisa de campo foi desenvolvida entre janeiro e março de 2009. Foram realizadas duas sessões de observação em cada uma das 10 academias e aplicados questionários junto aos seus gestores. Todos os entrevistados participaram da pesquisa com livre e esclarecido consentimento.
}

Pensar a Prática, Goiânia, v. 14, n. 2, p. 1-15, maio/ago. 2011 
fisioterapia e nutrição. O controle do pagamento das mensalidades, com valores acima de 200 reais, é feito por um software de gerenciamento especialmente desenvolvido para a academia.

\section{- Academia $C 2$}

Com quinze anos de mercado, com público diversificado, a academia conta com a oferta de mais de 13 práticas corporais orientadas por um quadro de 5 professores e 2 estagiários, além de 4 funcionários de apoio. Possui $497 \mathrm{~m}^{2}$, conta com uma filial em outro município da grande Goiânia e seu proprietário é professor de educação física. A mensalidade varia acima de 50 reais, não havendo um programa específico para o controle do pagamento. Apresenta convergência de comércio, agregando serviços como lanchonete e loja de artigos esportivos. Como estratégia de atração e retenção de alunos, a academia dá importância a investimentos em programas e práticas dirigidas a nichos específicos de consumidores - gestantes, infanto-juvenil, terceira idade etc. -, realizando também campanhas, distribuição de prêmios e aulas especiais.

\section{- Academia C3}

Estabelecida no mercado há seis anos, trabalham na academia 3 professores e 2 estagiários que, junto com outros 5 funcionários de apoio, atendem consumidores, predominantemente, de "meia idade" e, diferencialmente, idosos e gestantes. Oferecem diretamente os serviços de musculação, ginástica e hidroginástica, além de terceirizarem os serviços de RPG e hidroterapia. Desenvolvem programa de capacitação de seus professores através de cursos de curta duração e possuem forte ação de marketing interno visando a retenção de seus consumidores. A mensalidade cobrada na academia está na faixa de 100 a 150 reais, com gerenciamento realizado a partir de software específico. Seu proprietário é fisioterapeuta e a academia possui perto de $500 \mathrm{~m}^{2}$.

\section{- Academia C4}

A academia encontra-se no mercado há três anos, seu proprietário é um investidor, e conta com 41 funcionários, sendo 22 professores e 7 estagiários. Oferece 13 práticas que se revezam em ambientes específico, num espaço total de $800 \mathrm{~m}^{2}$. A academia promove ainda eventos regulares e conta com o serviço terceirizado de nutrição, além de uma loja de artigos esportivos. Na perspectiva da retenção de alunos, a academia renova permanentemente a oferta de seus programas de ginástica, bem como desenvolve programas dirigidos a nichos específicos de consumidores. O custo das mensalidades está na faixa de 100 a 150 reais e seu pagamento também é gerenciado a partir de software específico.

\section{- Academia C5}

Estabelecida há sete anos no mercado, a academia, que possui $800 \mathrm{~m}^{2}$, é bastante inovadora sob o ponto de vista arquitetônico. $\mathrm{O}$ ambiente interior é bastante iluminado e ventilado, com espelhos fartamente distribuídos, contando ainda com uma praça de alimentação e área verde. Oferta 12 serviços diferenciados - com a terceirização do spinning -, cuja prática é visível externamente por meio de sua fachada de vidro. $\mathrm{O}$ proprietário é professor de educação física e a academia conta com um número de 21 funcionários, sendo 12 professores e 3 estagiários. Atende a um público, 
10.5216/rpp.v14i2.12311

predominantemente, de "meia idade". A mensalidade cobrada, igualmente controlada a partir de software desenvolvido para tal, varia entre 100 e 150 reais.

Em geral, as academias centrais possuem características muito comuns, pois demandam grandes investimentos e um alto nível de racionalização do trabalho, contando com gestão profissional, pessoal qualificado, padrão de atendimento, planejamento de marketing, espaços planejados, equipamentos sofisticados etc. Quanto a estrutura física, com projeto arquitetônico próprio ao segmento, além de fachadas e mídias de sinalização externa que lhe conferem exposição, todas contam com estacionamento próprio e gozam de muita organização na recepção ao cliente, com atendentes uniformizadas, cômoda sala de espera, material informativo etc. Em sua maioria são climatizadas e de cores claras, traduzindo limpeza e ventilação. As salas são separadas por atividade e as divisórias compostas de material transparente a fim de garantir visibilidade a todos que estiverem no ambiente da academia. São equipadas por máquinas novas, de tecnologia recente e de fácil utilização. Os vestiários são amplos e com guarda volumes, atendendo ao público que vem para academia direto do trabalho, faculdade ou escola. Muitas oferecem outros serviços como lanchonetes, lojas de vestuário, lan house, brinquedoteca, enfim, buscam garantir a convergência de serviços. Em relação aos proprietários das academias, normalmente são investidores sem vínculo com a área da Educação Física. Os professores, todos com formação especializada, possuem jornadas de 16 a 25 horas semanais na academia e boa parte trabalham em outros lugares. Os alunos dessas academias constituem uma clientela bastante heterogênea, apesar de possuírem rituais de comportamento próximos, tecendo relacionamento formal, objetivo e direto, introspectivos e concentrados na atividade. Sua integração e sociabilidade ocorrem a partir de espaços e eventos especialmente organizados para tal fim, como estratégia planejada para garantir aderência à academia.

\section{As academias da periferia}

\section{- Academia P1}

Com cinco anos de funcionamento, inicialmente construída no quintal da casa do próprio proprietário, a academia foi se ampliando e ganhando novos espaços até incorporar o espaço antes residencial, possuindo um total de $300 \mathrm{~m}^{2}$. Para além da oferta original da musculação, foram agregadas também novas práticas, como ginástica, dança e lutas. Para atração do público feminino, houve ainda a separação dos aparelhos utilizados por este segmento, alocados em espaço específico a fim de se evitar o constrangimento e assédio antes presentes. A aparelhagem da academia, embora bem conservada, é antiga e obsoleta. O proprietário é também professor da academiada, empregando outro professor e um funcionário de apoio e limpeza. Cobrando uma mensalidade abaixo de 50 reais, a academia atende um público predominantemente formado por moradores do bairro.

\section{- Academia P2}

Situada na região comercial do bairro, a academia funciona a três anos, atendendo, sobretudo, a população local, oferecendo musculação, ergometria, dança e lutas. Possui uma área total de $400 \mathrm{~m}^{2}$. Entretanto, o espaço destinado aos aparelhos, relativamente 
10.5216/rpp.v14i2.12311

numerosos, porém antigos e reformados, é apertado e desorganizado, dificultando o fluxo dos alunos e seu correspondente atendimento. A recepção é composta por sistema informatizado e catraca digital, sob o controle de uma recepcionista, que junto ao dono da academia supervisiona todos os ambientes. O proprietário é formado em nível técnico e exerce também o papel de professor na academia, função que divide com mais outros 2 professores, estes com formação específica. Com mensalidade inferior a 50 reais, seu público é do próprio bairro.

\section{- Academia P3}

Com estrutura e organização peculiares em relação aos empreendimentos dessa categoria que se localizam em regiões periféricas, a academia tem menos de 1 ano no mercado, possui $1.180 \mathrm{~m}^{2}, 16$ funcionários, sendo 9 professores e 1 estagiário, ofertando 10 serviços diferenciados. Conta com serviços terceirizados ligados a alimentação, vestuário e avaliação física, configurando um aglomerado de serviços que atendem a uma clientela bastante heterogênea. $O$ valor da mensalidade varia entre 50 e 100 reais. Ocorre que a academia se localiza em um complexo viário de grande fluxo ao lado de um shopping center, o que garante a atração de consumidores de distintas regiões da cidade. A academia foi construída a partir de capital advindo de outros setores. Seu gestor e também proprietário não possui formação superior, valendo-se de consultoria especializada que o ajudou desde a concepção arquitetônica do espaço até a escolha dos equipamentos, bem como na implantação do negócio, no plano de gestão, seleção de pessoal e elaboração das estraégias de marketing.

\section{- Academia P4}

Funcionando há 10 anos, com uma área de $400 \mathrm{~m}^{2}$, salas amplas e arejadas a academia oferece os serviços de musculação, ginástica localizda, jump e dança, atendendo, em sua maioria, uma clientela do próprio bairro em que se localiza. Seus equipamentos são, em grande parte, reformados. A mensalidade cobrada é inferior a 50 reais. Seu proprietário, professor de Educação Física que já trabalhava na academia antes de adquiri-la, a partir da venda de propriedades imobiliárias, comprou e ampliou o negócio. Trabalham com ele outros 6 funcionários, sendo 3 professores e 1 estagiário.

\section{- Academia P5}

A academia é de propriedade de um professor de Educação Física que contraiu empréstimos para construção do empreendimento. Com área de $250 \mathrm{~m}^{2}$, funcionando em espaço alugado, a unidade conta com aparelhos novos e oferece apenas os serviços de musculação e ergometria, contando com orientação nutricional terceirizada. Seu público, do próprio bairro, dependendo da frequência semanal, paga uma mensalidade que oscila entre 50 e 100 reais. Seu proprietário diz primar pela organização e qualidade dos serviços oferecidos, investindo em sua formação como gestor, uma vez que ao dispor de uma estrutura simples e enxuta, enfrentas grandes dificuldades concorrenciais. Além dele trabalham na academia outros 5 funcionários, sendo 2 professores e 2 estagiários.

Diferente das academias centrais, as academias situadas na periferia da cidade, salvo exceções, não demandam grandes investimentos, envolvendo amadorismo e 
10.5216/rpp.v14i2.12311

processos simplificados de organização do trabalho. Apresentam fachadas que lhe garantem pouca exposição. Possuem recepção com atendentes que, não raro, são substituídas por um professor ou pelo próprio proprietário da academia. Não seguem padrões estéticos quanto a cores e organização das salas, pois esses fatores são determinados muitas vezes pelo imóvel que é alugado. A escolha dos equipamentos, a maioria usados, dá-se pelo capital disponível, tendo em vista outras despesas que influenciam diretamente no negócio, como locação, salário dos professores e outros. Quase sempre focam suas atividades nas práticas da musculação e ergometria, mas buscam também agregar práticas complementares como a dança e as lutas, pois vêem nessas modalidades a possibilidade de conquistarem novos alunos. Seus proprietários quase sempre são formados em Educação Física e exercem ao mesmo tempo o papel de gestor e professor, eventualmente, dedicando-se também a serviços de recepção e limpeza. Entendem a necessidade de processos organizados na administração da academia para que resista às dificuldades impostas pelo mercado e, embora de modo não bem planejado, estão em busca de inovações, investindo no negócio conforme suas possibilidades. Quanto ao quadro de professores não se tem a mesma uniformidade em relação a formação, ou seja, não são todos professores de Educação Física. A jornada de trabalho varia de 20 até 45 horas semanais na mesma academia, havendo também desempenho de atividades em outros estabelecimentos. O publico que freqüenta estas academias quase sempre é da região, se deslocam a pé e se conhecem, já que compõem comunidade próxima ao estabelecimento. $\mathrm{O}$ ambiente da academia constitui assim um espaço de sociabilidade com grande afetividade, percebida pela relação estabelecida entre os alunos e no seu tratamento com os professores, sobretudo, com o proprietário, quase sempre, morador do próprio bairro.

\section{Tendências de desenvolvimento}

O espaço urbano e a feitura da cidade são moldados pela circulação de mercadorias, como produto e condição dos processos sociais em transformação, seguindo uma lógica de desenvolvimento desigual (HARVEY, 2005), e é segundo esta lógica que se inscreve e se configura também a expansão da "Indústria do Fitness" em Goiânia. Com aproximadamente 1.2 milhões de habitantes, a capital goiana possui a proporção aproximada de uma academia para cada 10.000 habitantes, bem abaixo da proporção do mercado paulistano, o maior do país com uma academia para cada 5.500 habitantes. ${ }^{14}$ No entanto, inscrita no circuito nacional da "Indústria do Fitness" como um importante e emergente mercado, a cidade vem atraindo cada vez mais novos investimentos, com a abertura de academias de todo o tipo, das grandes redes às pequenas unidades.

Ao observarmos o mercado na cidade, com alta concentração de academias em regiões e lugares por onde mercadorias e consumidores circulam com maior fluidez, fica patente a disparidade da distribuição espacial das academias, opondo centro e periferia. Óbvio que tais oposições, as quais se soma a antinomia grandes e pequenas academias, não possuem limites rígidos, mas ilustram, sob o ponto de vista didático e analítico, as diferenças e desigualdades que apanham a Indústria do Fitness. Uma academia rica pode ser grande, com um público de consumidores de extratos

${ }^{14}$ Disponível em http://www.site.acadbrasil.com.br/. Acesso em 5 set. 2008.

Pensar a Prática, Goiânia, v. 14, n. 2, p. 1-15, maio/ago. 2011 
10.5216/rpp.v14i2.12311

econômicas superiores, como pode ser pequena, trabalhando na perspectiva do consumo em escala, dirigida às mesmas classes, porém, a nichos específicos no interior deste perfil, definidos por geração, gênero, estilos de vida etc.

A academia grande, aliás, a fim de ampliar o consumo, combina massificação e segmentação, diversificando a oferta de práticas que contemplam variados interesses e nichos. Regra geral, o que se verifica é a segmentação do mercado, seja por renda, por nichos ou por ambos os critérios sobrepostos. Neste cenário, os métodos de inovação mais freqüentes envolvem: a inovação organizacional que diz respeito à gestão e organização do trabalho em academias, com a diversificação e especialização do quadro profissional empregado; a inovação estrutural, que se refere ao projeto arquitetônico da academia e ao incremento dos seus equipamentos; e, a inovação estética, que objetiva a renovação da aparência sensível da mercadoria, neste caso, tanto da academia como das práticas corporais.

O fato é que uma academia grande jamais é uma academia pobre e, normalmente, situa-se nos centros mais dinâmicos da cidade. Já nas periferias, proliferam as academias pobres e pequenas. A despeito dos pequenos investimentos e limitada capacidade de inovação, em grande medida, apoiadas ainda numa lógica tradicional de organização do trabalho, muitas vezes sustentadas pela economia doméstica e familiar, as academias da periferia, estruturalmente limitadas, oferecem um leque de serviços focado em poucas práticas e serviços, geralmente, a musculação e a ergonomia. Assim, sobrevivem e se multiplicam em função do consumo local de moradores circunvizinhos e na prática de preços compatíveis com a renda deste segmento.

\section{Considerações finais}

Seguindo tendências que se manifestam em escala global, o desenvolvimento da Indústria do Fitness no Brasil e em Goiânia é acelerado, com a continua expansão de suas bases, tanto pela diversificação do núcleo original das práticas corporais ofertadas, definido pelas lutas, dança, ginástica e musculação, como pela racionalização do processo de produção e organização do trabalho, com a incorporação de métodos de inovação que acompanham as tendências mais gerais da reestruturação produtiva e gestão de negócios (HELOANI, 2003). A experiência das ultimas décadas revela que este crescimento responde às demandas de consumo impulsionadas pelos modismos do culto ao corpo, ${ }^{15}$ dando às academias um sentido operacional distinto da tradição de gestão personalizada, atualmente, com a inserção subordinada do professor de Educação Física. ${ }^{16}$

Assim, convivem hoje academias as mais modernas e também aquelas tradicionais. Isto varia de acordo com o local em que a academia se situa, com o perfil e

\footnotetext{
${ }^{15}$ O modismo do culto ao corpo ou "corpolatria", segundo Codo e Sene (1985), refere-se ao processo que, já na década de 1980, entre a classe média, transformava os hábitos relativos aos cuidados com o corpo em obsessão, uma verdadeira idolatria, uma patologia psico-social com fortes traços de individualismo, narcisismo e hedonismo.

${ }^{16}$ Ocorre que nos últimos anos investimentos mais elevados foram sendo requeridos na construção das academias de ginástica. Assim, o capital necessário para a abertura do negocio se eleva, dificultando o surgimento de novas academias de propriedade de professores de Educação Física (FURTADO, 2007).
}

Pensar a Prática, Goiânia, v. 14, n. 2, p. 1-15, maio/ago. 2011 
10.5216/rpp.v14i2.12311

poder aquisitivo de seus consumidores e com o tamanho do empreendimento. De qualquer maneira, o que percebemos é um processo de desenvolvimento desigual, com enormes disparidades no que se refere ao modelo de gestão, à estrutura, à tecnologia dos equipamentos, à quantidade de alunos e professores etc, mas, principalmente, no que se refere aos investimentos e faturamento de grandes e pequenas academias, o que implica na sua distribuição também desigual pela cidade, em áreas ricas e pobres, no centro e na periferia.

\section{Referências}

ADORNO, Theodor Wiesengrund; HORKHEIMER, Max. A indústria cultural: o esclarecimento como mistificação das massas. In: Dialética do esclarecimento: fragmentos filosóficos. Rio de Janeiro: Jorge Zahar, 1985. p. 113-156.

BRAVERMAN, Harry. Trabalho e capital monopolista: a degradação do trabalho no século XX. 3 ed. Rio de Janeiro: LTC, 1987.

CODO, Wanderley; SENNE, Wilson. O que é corpolatria. São Paulo: Brasiliense, 1985.

DA COSTA, Lamartine (Org.). Atlas do esporte no Brasil. Rio de Janeiro: CONFEF, 2006.

FURTADO, Roberto Pereira. O não-lugar do professor de educação física em academias de ginástica. 2007. Dissertação (Mestrado em Educação). Faculdade de Educação, Universidade Federal de Goiás, Goiânia, 2007.

GOIÂNIA. Prefeitura Municipal. Secretaria de Planejamento. Aspectos demográficos da população de Goiânia, por bairro, segundo o Censo 2000. Goiânia: SEPLAN, 2002.

HARVEY, David. Condição pós-moderna. 9 ed. São Paulo: Loyola, 2000.

A produção capitalista do espaço. São Paulo: Annablume, 2005.

HELOANI, Roberto. Gestão e organização no capitalismo globalizado: historia da manipulação psicológica no mundo do trabalho. São Paulo: Atlas, 2003.

ORTIZ, Renato. Mundialização e cultura. São Paulo: Brasiliense, 1994.

PINHEIRO, Ivan Antonio; PINHEIRO, Rodrigo Reska. Organização cientifica do trabalho reinventa um mercado tradicional: o caso do fitness. RAE eletrônica, v. 5, n. 2, p. 1-26, 2006. 
10.5216/rpp.v14i2.12311

SERVIÇO BRASILEIRO DE APOIO ÀS MICRO E PEQUENAS EMPRESAS. Fatores condicionantes e taxas de sobrevivênciae mortalidade das micro e pequenas empresas no Brasil 2003-2005. Brasília: SEBRAE, 2005.

\title{
THE FITNESS INDUSTRY AND ITS UNEVEN DEVELOPMENT: A STUDY OF THE GYMS IN THE CITY OF GOIANIA
}

\begin{abstract}
This article is the result of an investigation on the logical development of the "Industry's Fitness". From the case study, we collate the trends of expansion of this "Industry" with data on the context in Goiânia-GO. We built a quantitative characterization of the market and conducted a qualitative study involving interviews and observation, with 10 academies in the city. It was concluded that the growth of this sector follows the logic of uneven development, with the opposition of major academies, which show an enormous capacity for innovation, being distributed by the most dynamic centers of the city, and small academies that proliferated in the periphery based on traditional methods of organizing work and dependent on local consumption. Keywords: Fitness. Gyms. Goiânia.
\end{abstract}

\section{LA INDUSTRIA DEL FITNESS Y SU DESARROLLO DESIGUAL: UN ESTUDIO DE LOS GIMNASIOS EN LA CIUDAD DE GOIANIA}

Resumen: Este artículo es el resultado de una investigación sobre la lógica del desarrollo de la "Industria del Fitness". En el caso de estudio, síntesis de las tendencias de la expansión de esta "Industria" con los datos sobre el contexto en Goiânia-GO. Construimos una caracterización cuantitativa del mercado y llevó a cabo un estudio cualitativo con entrevistas y observación, con 10 academias de la ciudad. Se concluyó que el crecimiento de este sector sigue la lógica del desarrollo desigual, con la oposición de las academias más importantes, que muestran una enorme capacidad para la innovación, siendo distribuido por los centros más dinámicos de la ciudad, y las academias pequeños que proliferaron en la periferia sobre la base de los métodos tradicionales de organización del trabajo y dependiente en el consumo local.

Palabras clave: Fitness. Gimnasios. Goiânia.

Endereço para correspondência:

fernandom@unb.br

Fernando Mascarenhas, UNB

Universidade de Brasília, Faculdade de Educação Física

Campus Universitário Darcy Ribeiro

Asa Norte

70910-900 - Brasilia, DF - Brasil

Pensar a Prática, Goiânia, v. 14, n. 2, p. 1-15, maio/ago. 2011 